\title{
LV-PP-4-4
}

\section{Laparoscopic versus open liver resection for hepatocellular carcinoma: Long-term and short-term surgical outcomes depending on tumor size}

\author{
Olesya SOLOVYEVA, Mikhail EFANOV, Ivan KAZAKOV, Andrey VANKOVICH, Dmitriy KOVALENKO, \\ Anna KOROLEVA, Natalia ELIZAROVA, Natalia KULIKOVA, Alexander PETRIN, Ruslan ALIKHANOV* \\ Department of Hepatobiliary and Pancreatic Surgery, Moscow Clinical Scientific Center, Russia
}

Introduction: The aim of the study was to compare the short- and long-term outcomes of laparoscopic liver resection (LLR) and open liver resection (OLR) for hepatocellular carcinoma (HCC) and to identify patients who might gain more benefits from LLR depending on tumor size.

Methods: The demographic and peri-operative data, short-term surgical outcomes, and long-term oncological results of 80 patients who received liver resection for HCC between January 2015 and December 2020 were analyzed (LLR, n=56; OLR, n=24). The average size of tumor in both groups were assessed for comparison.

Results: The average size of tumor was $50 \mathrm{~mm}$ in LLR and $80.3 \mathrm{~mm}$ in OLR. LLR is associated with less blood loss ( $p<0.001)$, shorter length of hospital stay $(p<0.001)$, and lower morbidity rate $(p=0.034)$. The 5 -year overall survival (OS) rates in the LLR group were significantly higher than those in the OLR group ( $81.3 \%$ vs. $27.5 \% ; p=0.020)$ and 5 -year relapse free survival $(55.1 \%$ vs $31.4 \% ; p=0.020)$. The short-term outcomes were better in the LLR group in terms of blood loss, and length of hospital stay, and these benefits attenuated with advancing tumor size.

Conclusions: LLR for HCC is a safe and feasible procedure that has better short-term and long-term oncological outcomes in patients with tumor size less than $50 \mathrm{~mm}$. 